\title{
Two Clusters among Mycoplasma haemomuris Strains, Defined by the 16S-23S rRNA Intergenic Transcribed Spacer Sequences
}

\author{
Hinako SASHIDA $^{1)}$, Fumina SASAOKA ${ }^{1)}$, Jin SUZUKI ${ }^{1)}$, Masatoshi FUJIHARA ${ }^{1)}$, Kazuya NAGAI ${ }^{2)}$, Hiromi FUJITA ${ }^{3)}$, \\ Teruki KADOSAKA ${ }^{4)}$, Shuji ANDO ${ }^{5)}$ and Ryô HARASAWA ${ }^{1) *}$ \\ ${ }^{1)}$ Department of Veterinary Microbiology, Faculty of Agriculture, Iwate University, Morioka 020-8550, Japan \\ ${ }^{2)}$ Cryobiofrontier Research Center, Faculty of Agriculture, Iwate University, Morioka 020-8550, Japan \\ 3) Mahara Institute of Medical Acarology, Anan 779-1510, Japan \\ 4) Department of Infection and Immunology, Aichi Medical University, Nagakute 480-1195, Japan \\ ${ }^{5)}$ Department of Virology 1, National Institute of Infectious Diseases, Tokyo 162-8640, Japan
}

(Received 28 October 2012/Accepted 28 November 2012/Published online in J-STAGE 12 December 2012)

ABSTRACT. Mycoplasma haemomuris is a causative organism of infectious anemia or splenomegaly in rodents. Here, we report two distinct genetic groups among $M$. haemomuris strains detected from rats and mice, respectively, by examining the nucleotide sequences of the $16 \mathrm{~S}-23 \mathrm{~S}$ rRNA intergenic transcribed spacer region that has been shown to be a stable genetic marker for mycoplasma species. Our results may reveal host-tropism of each cluster of M. haemomuris strains, and suggest an idea to distinguish M. haemomuris into two different genetic clusters. KEY wORDS: hemoplasma, mycoplasma, rRNA

doi: 10.1292/jvms.12-0472; J. Vet. Med. Sci. 75(5): 643-648, 2013

Hemotropic mycoplasmas also called hemoplasmas are causative of infectious anemia in various mammalian animals [15]. Hemoplasma strains have been isolated as an anemic pathogen from rodents including mice, rats and hamsters and had once been identified by only microscopic observation of blood smears [18]. Hemoplasma infections in laboratory rodents have been concerned to undermine the validity of animal experiments $[1,13]$. They are often unrecognized, because of clinically silent infections. Such latent infections have been reported in Sprague-Dawley and Wistar rats [2, 3]. Currently, only one hemoplasma species Mycoplasma haemomuris Mayer 1921 formerly Bartonella muris or Haemobartonella muris, is established in rodents $[16,17]$. Nucleotide sequence of the 16S rRNA gene of $M$. haemomuris has been determined on the Shizuoka strain that was the only strain maintained in vivo at that time [19]. Subsequently, nucleotide sequence of the 16S-23S rRNA intergenic transcribed spacer (ITS) region of the same strain was defined [10]. However, genetic variation in the 16S rRNA gene or ITS region remains unexplored, because no other rodent hemoplasma strains except for the Shizuoka strain have been available. Here, we report two genetic clusters in $M$. haemomuris strains by examining nucleotide sequence of ITS region as well as the $16 \mathrm{~S}$ rRNA gene.

Anti-coagulated blood or spleen homogenates were obtained from black rats (Rattus rattus) or small field mice (Apodemus argenteus) infected with hemotropic mycoplasmas in Aomori and Fukushima Prefectures [5], and from

*Correspondence to: Harasawa, R., The Iwate Research Center for Wildlife Diseases, Morioka 020-0816, Japan.

e-mail: harasawa-tky@umin.ac.jp

(C)2013 The Japanese Society of Veterinary Science black rats with splenomegaly trapped in Okinawa Prefecture, Japan. Detail of these samples examined is given in Table 1. Blood smears were prepared for Giemsa staining. Total DNA was extracted from $200 \mu l$ of the whole blood or spleen homogenate by using the QIAamp DNA Blood Mini Kit (QIAGEN, Hilden, Germany) according to the manufacturer's instructions, eluting into $200 \mu \mathrm{l}$ of buffer AE, and stored at $-20^{\circ} \mathrm{C}$ until examination in the PCR assay.

Seven DNA samples were subjected to PCR to amplify entire region of the $16 \mathrm{~S}$ rRNA gene and ITS region. The PCR was carried out with $50-\mu l$ reaction mixtures containing $1 \mu l$ of DNA solution, $0.8 \mu l$ of Tks Gflex ${ }^{\mathrm{TM}}$ DNA polymerase ( 5 units $/ \mu l$ ), $25 \mu l$ of $2 \mathrm{X}$ Gflex PCR Buffer, $0.2 \mu l$ of relevant forward and reverse primers and water to a final volume of $50 \mu \mathrm{l}$. The forward (5'-AGAGTTTGATCCTGGCTCAG-3', equivalent to nucleotide numbers 11 to 30 of $M$. wenyonii(AY946266), or 5'- ATATTCCTACGGGAAGCAGC-3', equivalent to nucleotide numbers 328 to 347 of $M$. wenyonii), and reverse (5'- ACCGCAGCTGCTGGCACATA-3', equivalent to nucleotide numbers 503 to 522 of $M$. wenyonii, or 5'-TACCTTGTTACGACTTAACT-3', equivalent to nucleotide numbers 1446 to 1465 of $M$. wenyonii) ( $50 \mathrm{pmol} / \mu \mathrm{l}$ each) primers were used to amplify the 16S rRNA gene. On the other hand, ITS region was amplified by using forward primer Hemo16-23S-F (5'-GTTCCCAGGTCTTGTACACA-3') and reverse primer Hemo16-23S-R1 (5'-CAGTACTTGTTCACTGGTA-3') as described previously [6]. After initial denaturation at $94^{\circ} \mathrm{C}$ for $5 \mathrm{~min}$, the reaction cycle was carried out 30 times with denaturation at $98^{\circ} \mathrm{C}$ for $10 \mathrm{sec}$, annealing at $55^{\circ} \mathrm{C}$ for 60 sec and extension at $68^{\circ} \mathrm{C}$ for $30 \mathrm{sec}$ in a thermal cycler. The PCR products were fractionated on horizontal, submerged $1.0 \%$ SeaKem ME agarose gels (FMC Bioproducts, Rockland, ME, U.S.A.) in TAE (40 mM Tris, pH8.0, 5 mM 
Table 1. Source of the samples examined in the present study

\begin{tabular}{lllll}
\hline Sample designation & Host animal & $\begin{array}{l}\text { Place of animal trapped } \\
\text { (Prefecture, City) }\end{array}$ & Date of sampling & Condition of sample \\
\hline Ikemajima 5-1 & Black rat & Okinawa, Ikemajima & 1-Sep-10 & Whole blood \\
Ikemajima 14-1 & Black rat & Okinawa, Ikemajima & 1-Sep-10 & Whole blood \\
S151-2 & Small field mouse & Fukushima, Fukushima & 15-Dec-85 & Erythrocyte suspension \\
S152-2-4 & Small field mouse & Fukushima, Fukushima & 22-Mar-86 & Spleen homogenate \\
S152-5-7 & Small field mouse & Fukushima, Fukushima & 22-Mar-86 & Spleen homogenate \\
S154 & Black rat & Fukushima, Kawamata & 22-Feb-87 & Spleen homogenate \\
S159-11-13 & Small field mouse & Aomori, Owani & 29-May-88 & Spleen homogenate \\
\hline
\end{tabular}

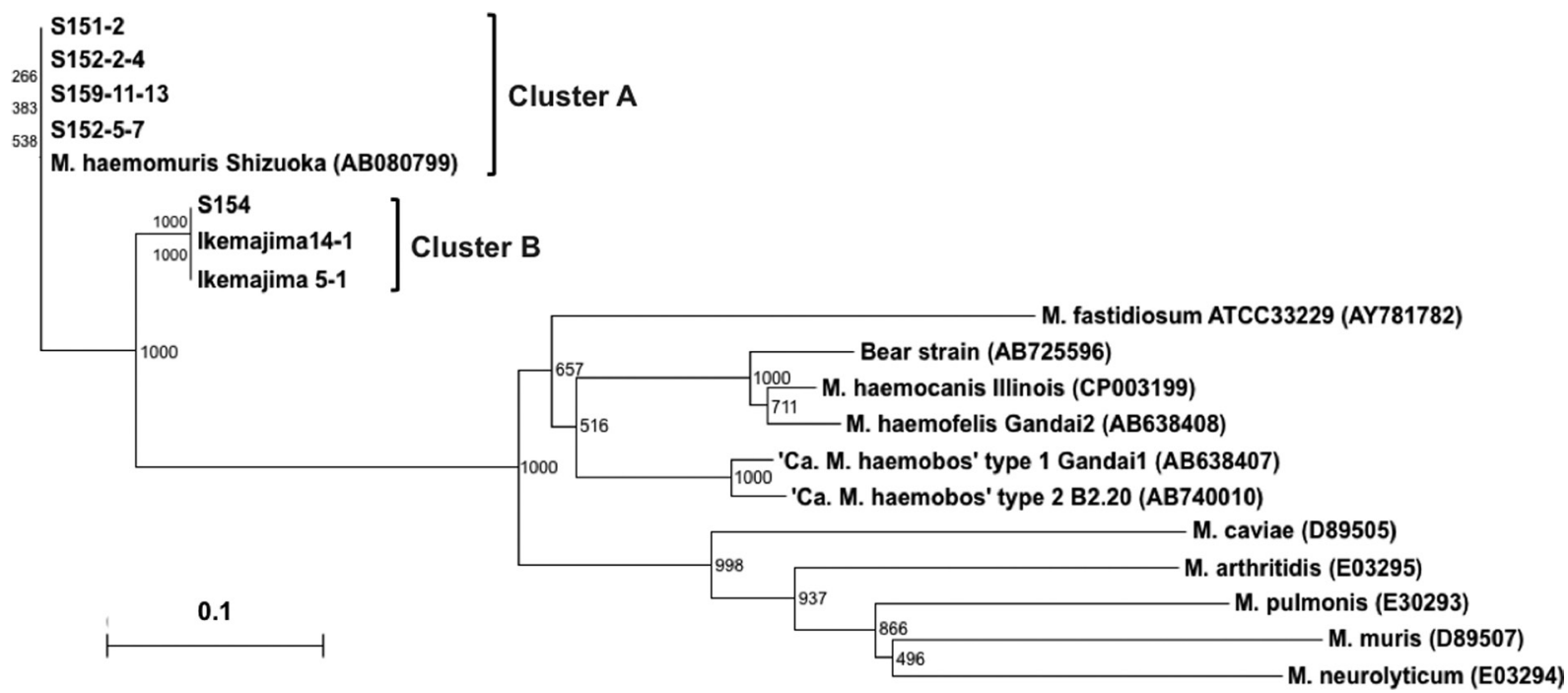

Fig. 1. Phylogenetic tree based on the hemoplasma ITS comparison with other rodent mycoplasmas. Following nucleotide sequence obtained from the DNA databases is shown with an accession number in parenthesis. They are M. pulmonis m53 (E03293), M. neurolyticum Sabin Type A (E03294), M. arthritidis PG6 (E03295), M. caviae G122 (D89505), M. muris RIII4 (D89507), M. haemomuris Shizuoka (AB080799), M. haemofelis Gandai2 (AB638408), Bear hemoplasma strain (AB725596), 'Ca. M. haemobos' type1 Gandai1 (AB638407) and 'Ca. M. haemobos' type 2 B2.20 (AB740010). Mycoplasma fastidiosum ATCC33229 (AY781782) was included as an out-group. Scale bar indicates the estimated evolutionary distance that was computed with CLUSTAL W [24] using neighbor-joining method [20]. Numbers in the relevant branches refer to the values of boot-strap probability of 1,000 replications.

sodium acetate and $1 \mathrm{mM}$ disodium ethylenediaminetetracetate) buffer at 50 volts for $60 \mathrm{~min}$. After electrophoresis, the gels were stained in ethidium bromide solution $(0.4 \mu \mathrm{g} / \mathrm{m} l)$ for $15 \mathrm{~min}$ and visualized under UV transilluminator. DNA in a clearly visible band was extracted by using NucleoSpin Extract II kit (Macherey-Nagel, Düren, Germany) and was subjected to direct sequencing in a 3500 Genetic Analyzer (Applied Biosystems, Foster City, CA, U.S.A.).

Almost entire nucleotide sequences of the 16S rRNA gene and ITS region of the seven strains were successfully determined. Nucleotide sequences of the 16S rRNA gene of these samples were almost identical (99\% homology) and also showed $99 \%$ homology to those of M. haemomuris Shizuoka strain (accession number U82963) isolated from a small field mouse in Japan [19]. This allowed us to classify the seven strains as M. haemomuris, though the Shizuoka strain used as a reference has been lost and unavailable (Rikihisa, per- sonal communication). Hemoplasma species has provisionally been classified or identified by only nucleotide sequence of the 16S rRNA gene because of uncultivable trait $[16,17]$.

The nucleotide sequences of ITS of the seven strains were compared with those of authentic rodent mycoplasma species in a phylogenetic tree that was generated with the neighbor-joining method [20] from a distance matrix corrected for nucleotide substitutions by the Kimura two-parameter model [14]. Phylogenetic analysis indicated that the seven isolates were divided into two clusters A and B (Fig. 1). Nucleotide sequence similarity between these two clusters was $84.9 \%$. This variation can be used for a genetic marker of $M$. haemomuris strains.

Next, we examined primary and secondary structures of the ITS region of the isolates. Nucleotide sequences of ITS region from the seven isolates were compared with six other hemoplasma sequences in an alignment created by 


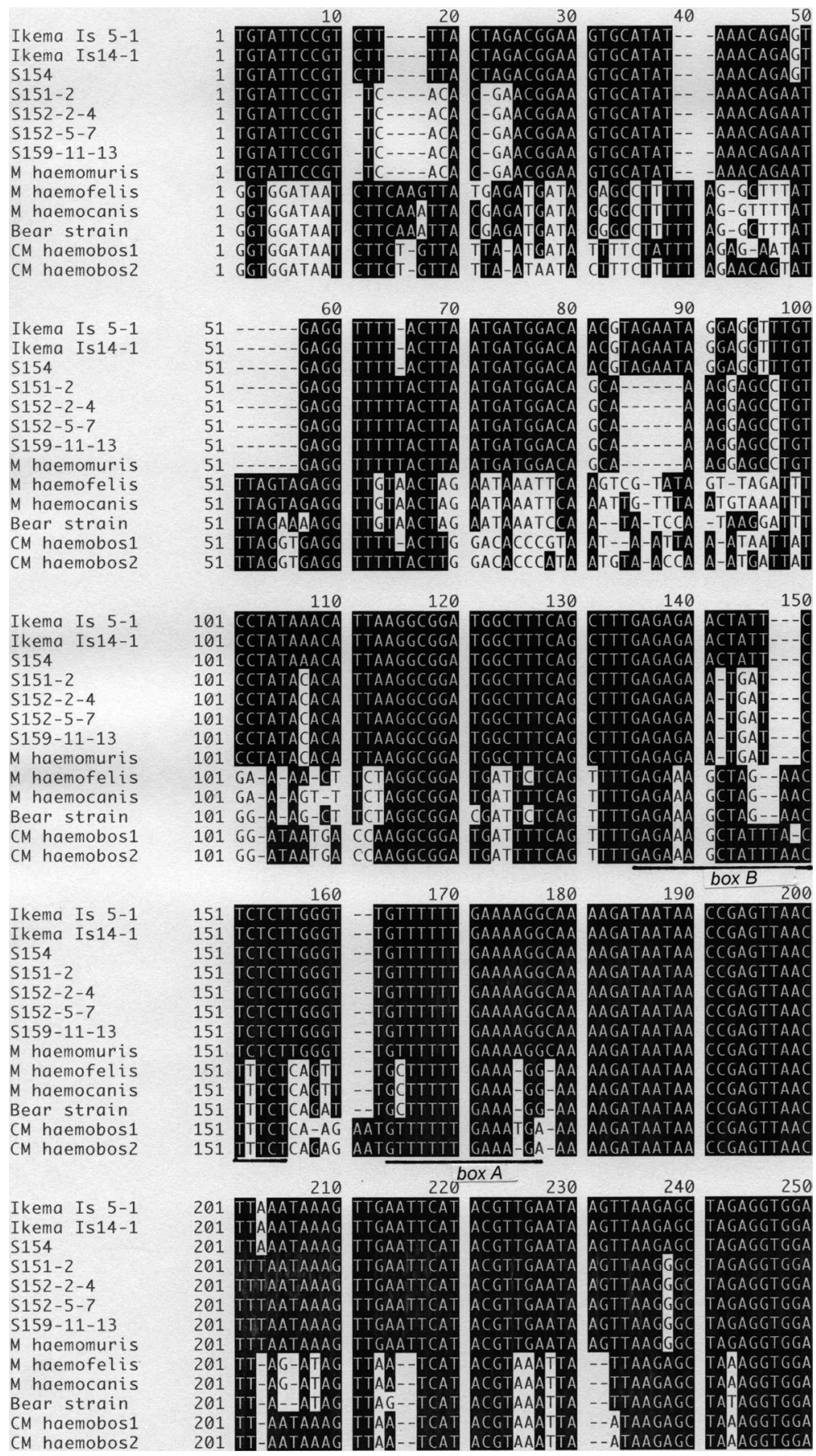

Fig. 2. Nucleotide variations appeared in alignment of the 13 ITS sequences from different hemoplasma strains. The nucleotide sequence numbers are given from a consensus sequence. Homologous nucleotides are shown as inverted characters. Dashes indicate nucleotide gaps between adjacent nucleotides introduced for the alignment. Ikema Is 5-1, Ikema Is 14-1, CM haemobos 1 and CM haemobos2 represent Ikemajima 5-1, Ikemajima 14-1 and 'Candidatus M. haemobos' type 1 and type 2 [22] strains, respectively.

CLUSTAL W [24]. Of the seven strains, ITS sequences of the five strains consisting of S151-2, S152-2-4, S152-5-7 and S159-11-13 were distinct from three other strains, S154,
Ikemajima 5-1 and Ikemajima 14-1 (Fig. 2). ITS sequences of these five strains were identical to those of $M$. haemomuris Shuzuoka strain. ITS region has been used for a comple- 


\section{Domain I Domain II Domain II Domain $\mathrm{V} \quad$ Domain $\mathrm{V} \quad$ Domain VI}

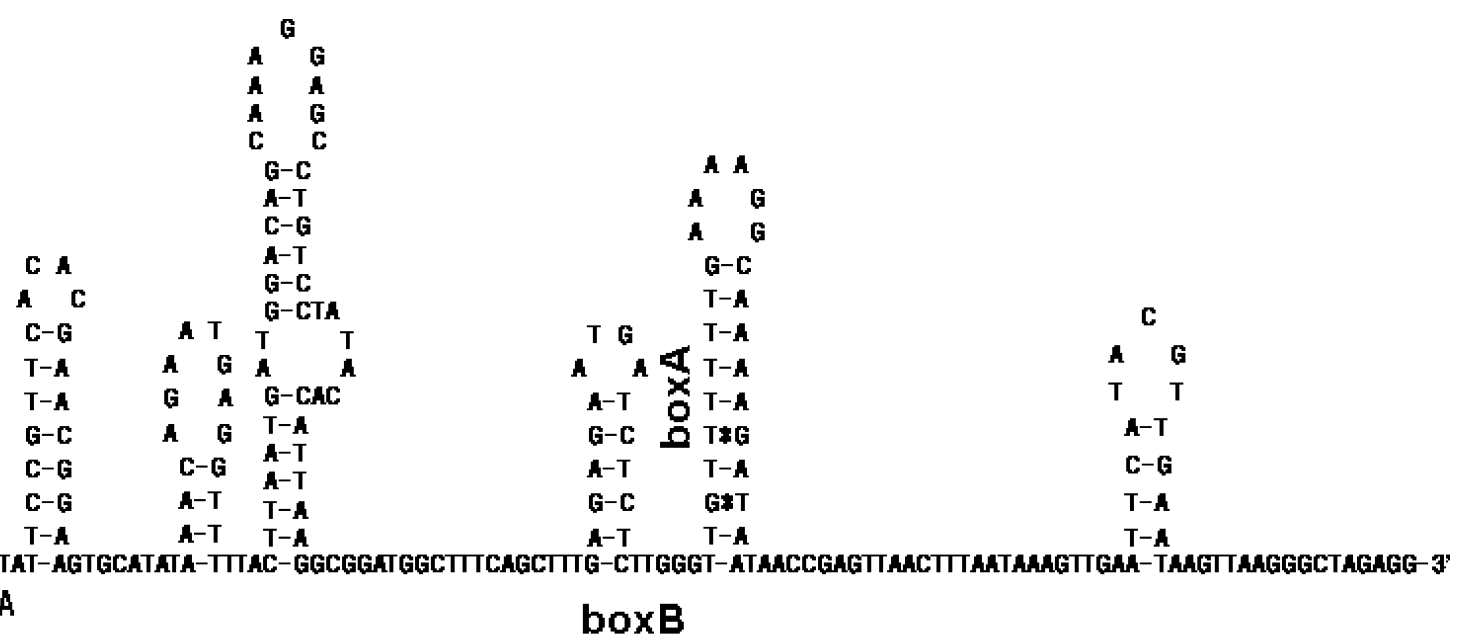
Cluster A

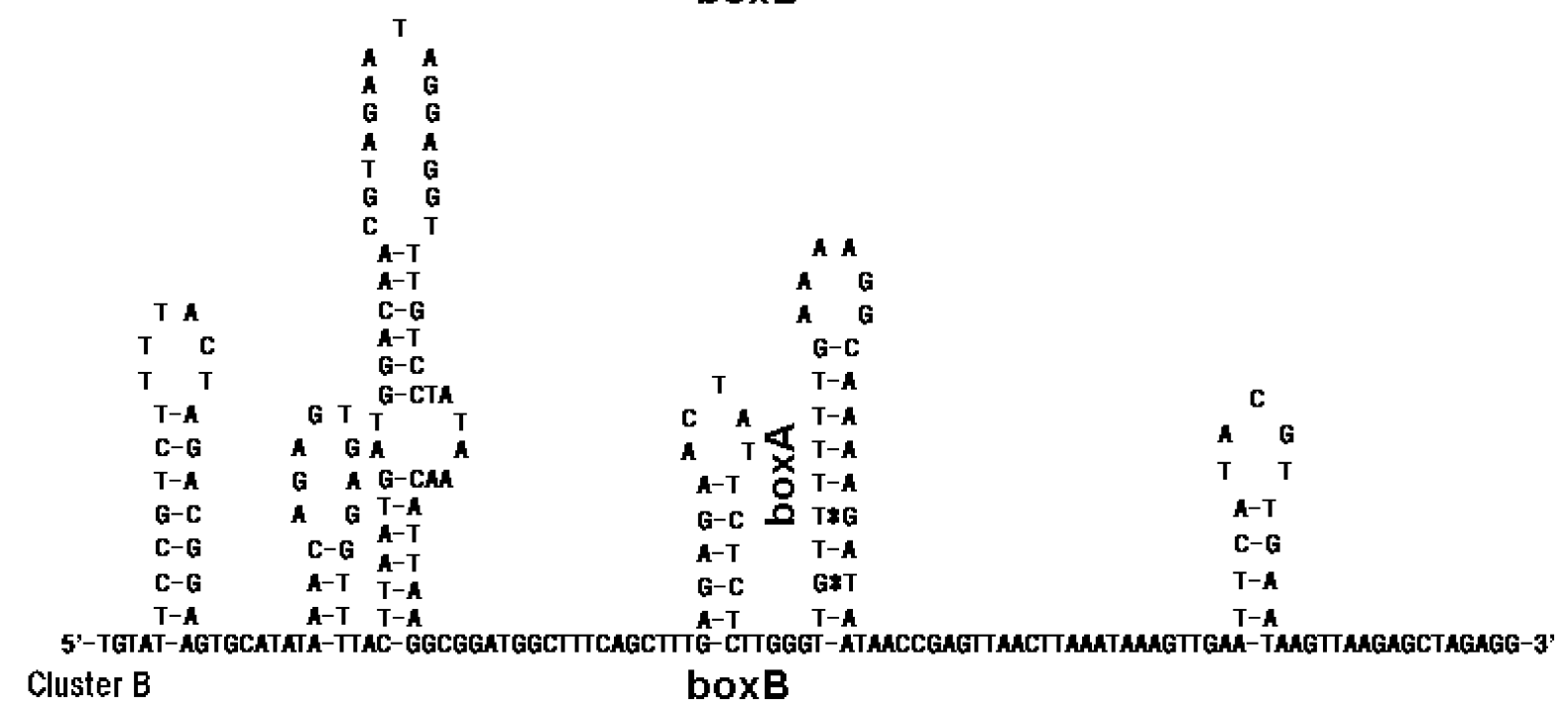

Fig. 3. Hypothetical secondary structures for the ITS regions of the two clusters, A (top) and B (bottom), of M. haemomuris. Canonical Franklin-Watson-Crick base-pairing is hyphened, and a wobble base-pairing tolerated in the secondary structure is shown by an asterisk. The box A was a part of the stem region of domain V, and box B was located between domains IV and V.

mentary genetic marker for identification and classification of mycoplasmas, since this region is characteristic to each Mycoplasma species [7-9, 11, 21, 25]. Thus, difference in nucleotide sequence of ITS region may raise a hypothesis that $M$. haemomuris species contains at least two distinct clusters. We also found the ITS region of seven strains lacked spacer tRNA gene, but contained box A and box B motifs previously identified in other mycoplasma species [12]. These motifs are obvious in the sequence alignment of ITS regions of these hemoplasmas.

The secondary structures of the ITS were predicted according to the algorithm of Zuker and Stiegler [26]. Six stem-loop domains were allocated in ITS region of the clusters A and B (Fig. 3). Domains V and VI were common between the clusters. Domain II was well conservative, despite a single nucleotide substitution at loop region. Stem re- gion of domain IV was well conserved between the clusters. Secondary structures in ITS region have sometime provided a key character to distinguish closely related species of mycoplasmas $[8,9,22]$. Thus, in addition to our previous illustration of ITS for M. haemomuris [10], the present analysis revealed existence of two genetically distinct clusters among M. haemomuris strains.

Collective analyses on the primary and secondary structures of ITS indicated $M$. haemomuris strains were divided into two clusters. This variation may not attribute to a geographical difference of locations where the hemoplasmas isolated, because cluster A included strains from Fukushima, Aomori and Shizuoka Prefectures, and cluster B included Fukushima and Okinawa Prefectures. Thus, this variation is most likely to depend on difference of natural host of hemoplasmas. In fact, cluster A strains have been isolated 

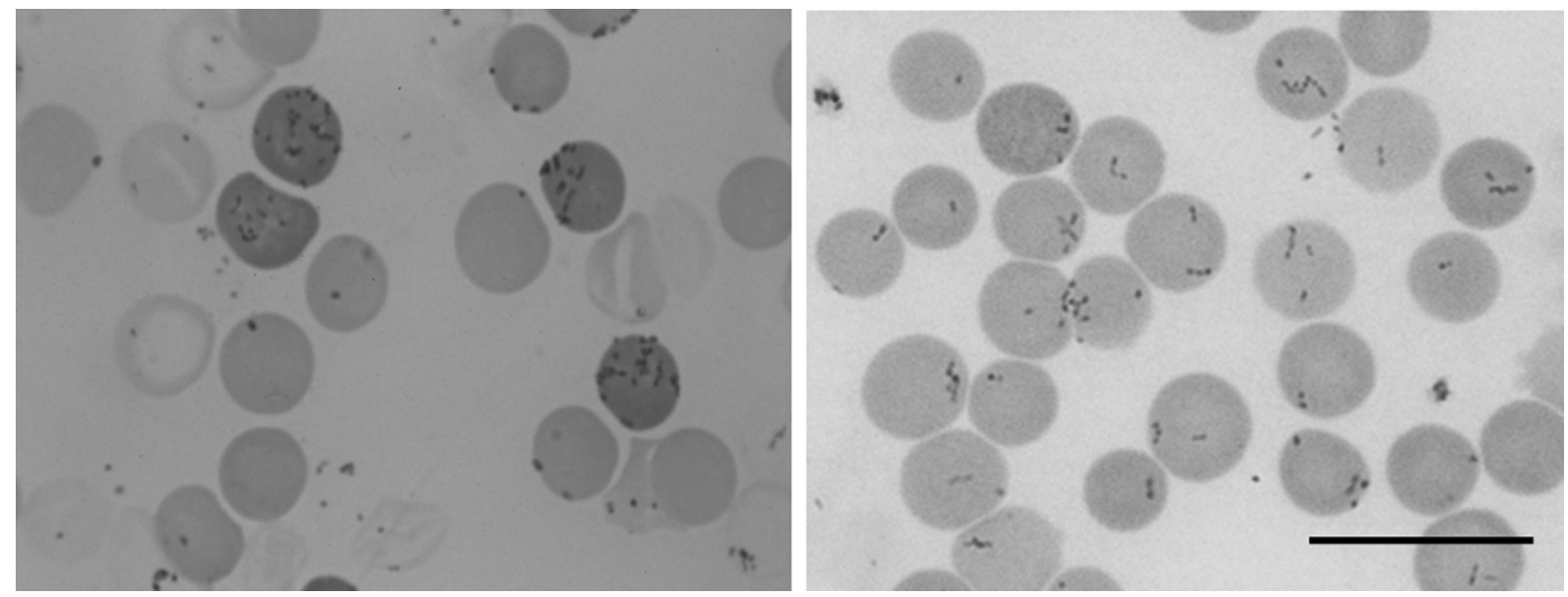

Fig. 4. Hemoplasma strains Ikemajima 5-1 (right) and S151-2 (left) from a black rat and a small field mouse, respectively, stained a deep purple color on blood smears. Bar represents $10 \mu \mathrm{m}$.

from small field mice, while cluster B was from black rats. Mycoplasma haemomuris, that was first observed in the blood of rats and named Bartonella muris ratti by Martin Mayer in 1921, was confirmed to be the causative agent of infectious anemia in albino rats following splenectomy [4]. Subsequently, another type of Bartonella morphologically distinct from $B$. muris ratti was found in the blood of albino mice by Schilling, and he called this variant as $B$. muris musculi [23]. Taken together, it turns out that the scientific designation, M. haemomuris, is composite of B. muris subsp. ratti in rat and $B$. muris subsp. musculi in mouse, despite possible cross-transfer between these animal species by experimental infection. Therefore, this raises a hypothesis that M. haemomuris Shizuoka strain isolated from a mouse may correspond to formerly B. muris musculi. In our microscopic observation, hemoplasma strains from each cluster appeared as tiny round bodies sometimes in chain within the red blood cells, though some of those from small filed mice might appear as projections from the red blood cell surface (Fig. 4). However, this minor difference may not be sufficient for differentiation of these two clusters on blood smears.

In conclusion, two genetic clusters of $M$. haemomuris were demonstrated by analyzing the primary and secondary structures of ITS region of $M$. haemomuris strains. Besides, our findings support the hypothesis that the cluster including M. haemomuris Shizuoka strain represents M. haemomuris subsp. musculi, and the another cluster corresponds to $M$. haemomuris subsp ratti. This may provide a clue to elucidate differences in severity of anemia in rodent, since virulence of these two clusters is currently unknown. This variation can also be used for a genetic marker for monitoring of $M$. haemomuris infections in laboratory rodents. The GenBank/ EMBL/DDBJ accession numbers appeared for the first time in this study are AB758434 through AB758440.

ACKNOWLEDGMENT. This study was partly supported by a Grant-in-Aid (No. 23658251) for Scientific Research of the Japan Society for the Promotion of Science from the
Ministry of Education, Culture, Sports, Science and Technology of Japan.

\section{REFERENCES}

1. Baker, H. J., Cassell, G. H. and Lindsy, J. R. 1971. Research complications due to Haemobartonella and Eperythrozoon infections in experimental animals. Am. J. Pathol. 64: 625-652. [Medline]

2. Bartlett, R. and Pease, P. 1975. Latent Haemobartonella muris infections: its transmission and decline in an inbred, ectoparasite-free strains of Wistar rat. Parasitology 71: 35-40. [Medline] [CrossRef]

3. Ford, A. C. and Murray, T. J. 1959. Studies on haemobartonella infection in the rat. Can. J. Microbiol 5: 345-350. [Medline] [CrossRef]

4. Ford, W. W. and Eliot, C. P. 1928. The transfer of rat anemia to normal animals. J. Exp. Med. 48: 475-492. [Medline] [CrossRef]

5. Fujita, H., Watanabe, Y. and Takada, N. 1995. Prevalence and properties of Haemobartonella-like microorganisms in field rodents in Fukushima Prefecture, Japan. Jpn. J. Sanit. Zool. 46: $159-162$.

6. Harasawa, R. 1996. PCR: application of nested PCR to detection of mycoplasmas. pp.75-79. In: Molecular and Diagnostic Procedures in Mycoplasmology, vol. 2 (Razin, S. and Tully, J. G. eds.), Academic Press, New York.

7. Harasawa, R. 1999. Genetic relationships among mycoplasmas based on the 16S-23S rRNA spacer sequence. Microbiol. Immunol. 43: 127-132. [Medline]

8. Harasawa, R. and Kanamoto, Y. 1999. Differentiation of two biovars of Ureaplasma urealyticum based on the 16S-23S rRNA intergenic spacer region. J. Clin. Microbiol. 37: 4135-4138. [Medline]

9. Harasawa, R., Hotzel, H. and Sachse, K. 2000. Comparison of the 16S-23S rRNA intergenic spacer regions among strains of the Mycoplasma mycoides cluster, and reassessment of the taxonomic position of Mycoplasma sp. bovine group 7. Int. J. Syst. Evol. Microbiol. 50: 1325-1329. [Medline] [CrossRef]

10. Harasawa, R., Kawahara, M. and Rikihisa, Y. 2002. Characteristics of the 16S-23S rRNA intergenic spacer region of Myco- 
plasma haemomuris, previously classified as 'Haemobartonella muris'. J. Vet. Med. Sci. 64: 1161-1164. [Medline] [CrossRef]

11. Harasawa, R., Pitcher, D. G., Ramirez, A. S. and Bradbury, J. M. 2004. A putative transposase gene in the $16 \mathrm{~S}-23 \mathrm{~S}$ rRNA intergenic spacer region of Mycoplasma imitans. Microbiology 150: 1023-1029. [Medline] [CrossRef]

12. Harasawa, R., Uemori, T., Asada, K., Kato, I. and Shiragami, N. 1992. 'boxA'-like sequence between the $16 \mathrm{~S} / 23 \mathrm{~S}$ spacer in the rRNA operon. FEBS Lett. 297: 209-211. [Medline] [CrossRef]

13. Kessler, W. R. 1943. Studies on experimental Bartonella muris anemia in the albino rat. II. Latent infection and resistance. $J$. Infect. Dis. 73: 77-84. [CrossRef]

14. Kimura, M. 1980. A simple method for estimating evolutionary rates of base substitutions through comparative studies of nucleotide sequences. J. Mol. Evol. 16: 111-120. [Medline] [CrossRef]

15. Messick, J. B. 2004. Hemotrophic mycoplasmas (hemoplasmas): a review and new insights into pathogenic potential. Vet. Clin. Pathol. 33: 2-13. [Medline] [CrossRef]

16. Neimark, H., Johansson, K. E., Rikihisa, Y. and Tully, J. G. 2001. Proposal to transfer some members of the genera Haemobartonella and Eperythrozoon to the genus Mycoplasma with the descriptions of 'Candidatus Mycoplasma haemofelis', 'Candidatus Mycoplasma haemomuris', 'Candidatus Mycoplasma haemosuis' and 'Candidatus Mycoplasma wenyonii'. Int. J. Syst. Evol. Microbiol. 51: 891-899. [Medline] [CrossRef]

17. Neimark, H., Johansson, K. E., Rikihisa, Y. and Tully, J. G. 2002. Revision of haemotrophic mycoplasma species names. Int. J. Syst. Evol. Microbiol. 52: 683. [Medline]

18. Noguchi, H. 1928. Etiology of Oroya fever. XI. Comparison of Bartonella bacilliformis and Bartonella muris. Cultivation of Bacterium murium, N. sp. J. Exp. Med. 47: 235-243. [Medline] [CrossRef]

19. Rikihisa, Y., Kawahara, M., Wen, B., Kociba, G., Fuerst, P., Kawamori, F., Suto, C., Shibata, S. and Futohashi, M. 1997. Western immunoblot analysis of Haemobartonella muris and comparison of 16S rRNA gene sequences of H. muris, H. felis, and Eperythrozoon suis. J. Clin. Microbiol. 35: 823-829. [Medline]

20. Saitou, N. and Nei, M. 1987. The neighbor-joining method: a new method for reconstructing phylogenetic trees. Mol. Biol. Evol. 4: 406-425. [Medline]

21. Sasaoka, F., Suzuki, J., Fujihara, M., Watanabe, Y., Nagai, K. and Harasawa, R. 2012. Examination of the 16S-23S rRNA intergenic spacer sequences of 'Cadidatus Mycoplasma haemobos' and Mycoplasma haemofelis. J. Vet. Med. Sci. 74: 83-87. [Medline] [CrossRef]

22. Sasaoka, F., Suzuki, J., Watanabe, Y., Fujihara, M., Nagai, K., Hirata, T. and Harasawa, R. 2013. Two genotypes among 'Candidatus Mycoplasma haemobos' strains based on the 16S23S rRNA Intergenic spacer sequences. J. Vet. Med. Sci. 75: (in press) [PMID: 23064449].

23. Schilling, V. 1929. Weitere beiträge zur Bartonella muris ratti, ihre übertragung auf weisse Mäuse und eine eigene Bartonella muris musculi N. sp. bei splenektomieten weissen Mäusen. Klin. Wochenschr. 8: 55-58. [CrossRef]

24. Thompson, J. D., Higgins, D. G. and Gibson, T. J. 1994. CLUSTAL W: improving the sensitivity of progressive multiple sequence alignment through sequence weighting, position-specific gap penalties and weight matrix choice. Nucleic Acids Res. 22: 4673-4680. [Medline] [CrossRef]

25. Volokhov, D. V., Simonyan, V., Davidson, M. K. and Chizhikov, V. E. 2012. RNA polymerase beta subunit (rpoB) gene and the 16S-23S rRNA intergenic transcribed spacer region (ITS) as complementary molecular markers in addition to the $16 \mathrm{~S}$ rRNA gene for phylogenetic analysis and identification of the species of the family Mycoplasmataceae. Mol. Phylogenet. Evol. 62: 515-528. [Medline] [CrossRef]

26. Zuker, M. and Stiegler, P. 1981. Optimal computer folding of large RNA sequences using thermodynamics and auxiliary. Nucleic Acids Res. 9: 133-148. [Medline] [CrossRef] 